\title{
PREVALENCE OF DENTAL CARIES AMONG PUBLIC SCHOOL CHILDREN IN EASTERN NEPAL
}

\author{
TK Bhagat ${ }^{1 *}$, A Shrestha ${ }^{1}$ \\ ${ }^{1}$ Department of Public Health Dentistry, B.P. Koirala Institute of Health Sciences, Dharan, Nepal \\ *Correspondence to: Dr. Tara Kant Bhagat, B.P. Koirala Institute of Health Sciences, Dharan, Nepal. \\ Email:drtarakant@gmail.com
}

\begin{abstract}
To assess the prevalence of dental caries among public school children of eastern Nepal using DMFT and dft index. Methods: Six hundred and sixty six school children were examined for decayed missing and filled teeth. Decayed, Missing and Filled Teeth (DMFT), decayed and filled teeth (dft) and prevalence were calculated. Results: The mean decayed and filled teeth were 1.82 whereas mean Decayed, Missing and Filled Teeth were 0.37.The prevalence of dental caries were $60.3 \%$ and $55.6 \%$ in the primary and permanent dentition respectively. Conclusion: The prevalence of dental caries was low in permanent dentition compared to primary dentition.
\end{abstract}

Key Words: Dental caries, Public school, Sunsari.

\section{INTRODUCTION}

Dental caries is the most common chronic infectious disease of oral hard tissues in developed as well as in developing countries. It varies from place to place as well as among gender and various age groups. Children are the ones who are most commonly afflicted by the disease. DMFT (Decayed, Missing and Filled Teeth) and dft (decayed, filled teeth) indices have been widely used to assess dental caries in permanent and primary teeth respectively. DMFT/dft gives out average or mean caries prevalence in any population. The World Health Organization (WHO) had set a target of achieving a below 3 DMFT for children aged 12 years by the year 2000. ${ }^{1}$ Studies regarding dental caries in Nepal are mostly focused to the central region. Therefore, the purpose of the present study was to assess the prevalence of dental caries among public school children of Sunsari and Dhankutta using DMFT and dft indices.

\section{MATERIALS AND METHODS}

This cross-sectional study was conducted on a randomly selected sample of school children in the Dhankutta and Sunsari districts of eastern Nepal. Six public schools were selected under a school health program through a convenience sampling method. Written consent was obtained from the schools as well as the guardians of the children. Ethical clearance was obtained from the IERB (Institutional Ethics Review Board, BPKIHS Dharan). A total of 666 children, whose parent had consented, took part in the study. Oro-dental examinations were carried out using a plane mirror and ballpoint probe under adequate daylight. Radiographs were not taken. The number of carious, missing and filled teeth and surfaces were recorded on examination forms, as per WHO guidelines. Due to the difficulty in distinguishing between teeth extracted for caries and exfoliation, the missing component for primary dentition was not recorded. ${ }^{2}$ For primary dentition, dft/dfs (decayed filled teeth/surface index) and for permanent dentition DMFT/DMFS (Decayed Missing Filled Teeth/Surfaces index) were used as the standard tool to record dental status of the children. Data were entered into the computer and statistical analyses were carried out using SPSS 20. Descriptive statistics such as mean and standard deviation as well as independent sample $t$ test were done. The level of significance was taken as $\mathrm{p}<0.05$.

\section{RESULTS}

A total of 666 children participated in the study with a male female ratio of $1: 1$. It was observed that $4.2 \%$ had primary dentition, $82.4 \%$ had mixed dentition and $13.4 \%$ had permanent dentition. Hence, 577 children were assessed for decay teeth (dt), filled teeth(ft), and dft whereas 638 were assessed for DT, (missing teeth) MT, FT, and DMFT.

The mean dft and dfs was 1.82 and 3.05 respectively. The prevalence of dental caries was $60.3 \%$ (Table 1 ). The mean dt, $\mathrm{ft}$ and $\mathrm{dft}$ among males were $1.80,0.03$ and 1.84 respectively. Similarly, the mean $\mathrm{dt}$, ft and dft among females were 1.74, 0.02 and 1.80 respectively. There was no significant difference in the caries status among the males and females in the primary dentition (Table 3).

The mean DMFT was 0.37 and DMFS was 0.42 . The prevalence of dental caries was $55.6 \%$ (Table 2 ). When the caries status was compared between genders, it was observed that females had higher DT and DS as well as higher DMFT/DMFS compared to males which was statistically significant (Table 4). None of the 
children had missing permanent teeth.

Table 1: Mean decayed and filled teeth in primary dentition

\begin{tabular}{|l|l|}
\hline & Mean and SD \\
\hline $\mathrm{dt}$ & $1.77 \pm 2.52$ \\
\hline $\mathrm{ft}$ & $0.03 \pm 0.21$ \\
\hline $\mathrm{dft}$ & $1.82 \pm 2.57$ \\
\hline $\mathrm{ds}$ & $2.92 \pm 4.98$ \\
\hline $\mathrm{fs}$ & $0.04 \pm 0.28$ \\
\hline $\mathrm{dfs}$ & $3.05 \pm 5.18$ \\
\hline Prevalence of dental caries & $60.3 \%$ \\
\hline
\end{tabular}

Table 2: Mean decayed, missing and filled teeth in permanent dentition

\begin{tabular}{|l|l|}
\hline & Mean and SD \\
\hline DT & $0.36 \pm 0.85$ \\
\hline MT & 0 \\
\hline FT & $0.01 \pm 0.10$ \\
\hline DMFT & $0.37 \pm 0.87$ \\
\hline DS & $0.40 \pm 1.06$ \\
\hline MS & 0 \\
\hline FS & $0.01 \pm 0.10$ \\
\hline DMFS & $0.42 \pm 1.08$ \\
\hline Prevalence of dental caries & $55.6 \%$ \\
\hline
\end{tabular}

Table 3: Comparison of $\mathrm{dt}$, $\mathrm{ft}$, $\mathrm{dft}, \mathrm{ds}$, fs and $\mathrm{dfs}$ between male and female

\begin{tabular}{|l|l|l|l|l|l|}
\hline & Male & Female & $\begin{array}{c}\mathrm{t} \\
\text { value }\end{array}$ & $\begin{array}{c}\mathrm{p} \\
\text { value }\end{array}$ & $95 \% \mathrm{CI}$ \\
\hline $\mathrm{dt}$ & $1.80 \pm 2.52$ & $1.74 \pm 2.52$ & 0.261 & 0.794 & -0.358 to 0.468 \\
\hline $\mathrm{ft}$ & $0.03 \pm 0.26$ & $0.02 \pm 0.14$ & 0.818 & 0.414 & -0.020 to 0.049 \\
\hline $\mathrm{dft}$ & $1.84 \pm 2.54$ & $1.80 \pm 2.59$ & 0.163 & 0.870 & -0.386 to 0.456 \\
\hline $\mathrm{ds}$ & $2.91 \pm 4.76$ & $2.93 \pm 5.20$ & -0.070 & 0.944 & -0.846 to 0.787 \\
\hline $\mathrm{fs}$ & $0.03 \pm 0.26$ & $0.04 \pm 0.31$ & -0.118 & 0.906 & -0.050 to 0.045 \\
\hline $\mathrm{dfs}$ & $2.96 \pm 4.82$ & $3.15 \pm 5.52$ & -0.439 & 0.661 & -1.038 to 0.659 \\
\hline
\end{tabular}

Table 4: Comparison of DT, MT, FT, DMFT, DS, MS, FS and DMFS between male and female

\begin{tabular}{|l|l|l|l|l|l|}
\hline & Male & Female & $\begin{array}{c}\mathrm{t} \\
\text { value }\end{array}$ & $\begin{array}{c}\mathrm{p} \\
\text { value }\end{array}$ & $95 \%$ CI \\
\hline DT & $0.27 \pm 0.76$ & $0.45 \pm 0.93$ & -2.771 & $0.006^{*}$ & -0.319 to -0.054 \\
\hline MT & 0.00 & $0.00 \pm 0.05$ & -1.016 & 0.310 & -0.009 to 0.003 \\
\hline FT & $0.01 \pm 0.78$ & $0.01 \pm 0.12$ & -0.408 & 0.683 & -0.020 to 0.013 \\
\hline DMFT & $0.27 \pm 0.78$ & $0.46 \pm 0.95$ & -2.753 & $0.006^{*}$ & -0.326 to -0.055 \\
\hline DS & $0.32 \pm 0.96$ & $0.51 \pm 1.15$ & -2.321 & $0.021^{*}$ & -0.360 to -0.030 \\
\hline MS & 0.00 & 00 & - & - & - \\
\hline FS & $0.01 \pm 0.07$ & $0.01 \pm 0.12$ & -0.408 & 0.683 & -0.020 to 0.013 \\
\hline DMFS & $0.32 \pm 0.97$ & $0.52 \pm 1.17$ & -2.322 & $0.021^{*}$ & -0.366 to -0.031 \\
\hline
\end{tabular}

*significant $(p<0.05)$

\section{DISCUSSION}

Dental caries prevalence and severity was investigated using $\mathrm{dft}$ and DMFT indices. The observed dft and DMFT values of the children were well within the national ${ }^{3}$ and WHO goals. ${ }^{4}$ The $\mathrm{dft}$ value was 1.84 which was less compared to the study by Salman FD. ${ }^{5}$ The DMFT value was 0.32 which was similar to the study by Baginska et $\mathrm{al}^{6}$ but was less compared to others. ${ }^{7-11}$ It was observed that $\mathrm{dt}$, $\mathrm{ft}$ and $\mathrm{dft}$ were more in males compared to females which was similar to other studies ${ }^{5,12}$ whereas ds and dfs were more in females compared to males. Females had higher DT and DS as well as higher DMFT/DMFS compared to males which was opposite to the study by Salman FD. ${ }^{5}$ The prevalence of dental caries in permanent dentition was $55.6 \%$ which was high compared to that reported by others ${ }^{13,14}$ but was lower compared to many studies..$^{7-10,15,16}$ Similarly, the prevalence of dental caries was $60.3 \%$ in primary dentition which was similar to that of the study by Zmarandache et al. ${ }^{16}$ It was more compared to the study by Yee et al. ${ }^{3}$ but less compared to that by Saravanan et al. ${ }^{13}$

\section{CONCLUSION}

The study showed a low dft/DMFT and lower prevalence of dental caries which is encouraging but at the same time the burden of treatment was high as decayed component constituted the major portion of $\mathrm{dft}$ and DMFT with negligible proportion of filled component. Hence, focus should be on prevention through health education rather than on treatment which a developing country like Nepal cannot afford. 


\section{REFERENCES}

1. Barmes DE. Indicators for oral health and their implications for developing countries. Int Dent J 1983;33:60-66.

2. Pine C. Community Oral Health. Public Health Aspects of Oral Diseases and Disorders- Dental Caries. Quintessence Publishing Co. Ltd. Germany, 2nd ed. 2007:166.

3. Yee R, Mishra P. Nepal Oral National Pathfinder Survey 2004. Int Dent J 2006;56(4):196-202.

4. Bratthall D. Introducing the Significant Caries Index together with a proposal for a new global oral health goal for 12-yearolds. International Dental Journal 2000;50(6):378-84.

5. Salman FD. Prevalence of dental caries among primary school children in Thamar Governorate in Republic of Yemen. Al-Rafidain Dent J 2003;3(2):127-32.

6. Bagińska J, Linczuk E. Dental caries profile among 6-8year old children from Bialystok District, Poland. Prog Health Sci 2013;3(2):53-8.

7. Meghashyam B, Nagesh L, Ankola A. Dental caries status and treatment needs of children of fisher folk communities, residing in the coastal areas of Karnataka region, south India. West Indian Med J 2007;56:96-8.

8. Kulkami SS, Deshpande SD. Caries prevalence and treatment needs in 11-15 year old children of Belgaum city. J Indian Soc Pedod Prev Dent 2002;20:12-5.

9. Dash JK, Sahoo PK, Bhuyan SK, Sahoo SK. Prevalence of dental caries and treatment needs among children of Cuttack (Orissa). J Indian Soc Pedo Prev Dent. 2002;20:139-43.
10. Mafuvadze BT, Mahachi L, Mafuvadze B. Dental caries and oral health practice among 12 year old school children from low socio-economic status background in Zimbabwe. Pan African Medical Journal 2013;14:164. (doi:10.11604/ pamj.2013.14.164.2399.)

11. Yee R, David J, Khadka R. Oral cleanliness of 12-13-yearold and 15-year-old school children of Sunsari District, Nepal. J Indian Soc Pedod Prev Dent 2006;24(3):146-51.

12. Nuca C, Amariei C, Borutta A, Petcu L. Prevalence and Severity of Dental Caries in 6 and 12 Year Old Children in Constanta District (Urban Area), Romania. OHDMBSC 2009; 8(3):19-24.

13. Saravanan S, Madivanan I, Subashini B, Felix JW. Prevalence pattern of dental caries in the primary dentition among school children. Indian J Dent Res 2005;16:140-6.

14. Frencken J, Manji F, Mosha H. Dental caries prevalence amongst 12-year-old urban children in East Africa. Community Dent Oral Epidemiol 1986;14:94-8.

15. Rao A, Sequeira SP, Peter S. Prevalence of dental caries among school children of Moodbidri. J Indian Soc Pedod Prev Dent. 1999; 17:45-8.

16. Zmarandache DDD, Luca R, Chis AC, Farcasiu C. Carious activity in 12 year-old children from Slatina, Romania. International Journal of Medical Dentistry, 2012;2(1):27-32. 